\title{
An explanation for some fallstreak clouds
}

\author{
R. M. Worthington \\ RASC, Kyoto University, Uji, Kyoto 611-0011, Japan
}

Received: 24 August 2001 - Revised: 3 January 2002 - Accepted: 9 January 2002

\begin{abstract}
Fallstreak cirrus clouds are associated with supersaturated air, together with waves, instabilities and/or turbulence; however, their precise cause is usually uncertain. This paper uses already-published satellite, radiosonde and radar data, reanalysed to study some large fallstreaks which had been previously overlooked. The fallstreaks - up to $60 \mathrm{~km}$ long with a parent cloud $20 \mathrm{~km}$ wide - are caused by lifting and/or turbulence from a mountain wave, rather than, for example, Kelvin-Helmholtz instabilities. If turbulent breaking of mountain waves affects ice particle formation, this may be relevant for the seeder-feeder effect on orographic rain, and the efficiency of mountain-wave polar stratospheric clouds for ozone depletion.
\end{abstract}

Key words. Meteorology and atmospheric dynamics (turbulence; waves and tides) - Atmospheric composition and structure (cloud physics and chemistry)

\section{Introduction}

Fallstreak clouds, also known as "mare's-tail cirrus" or "cirrus uncinus", can be a striking sight. They are curved streaks of falling ice crystals, sometimes with a parent, cumulus cloud above; photographs are shown by, for example, Ludlam (1956), Yagi (1969), Kon et al. (1973), Gedzelman (2000), Atlas (2001), and many cloud atlases and web-sites.

Fallstreaks in the upper troposphere are associated with air, supersaturated relative to ice, that encounters lifting and/or turbulence, and releases ice crystals (Heymsfield et al., 1975a, b, c). Two possible underlying causes are KelvinHelmholtz instabilities (KHI) and mountain waves, although the evidence for either is only circumstantial - fallstreaks are usually studied as an almost separate, cloud-physics phenomenon.

The fact that parent clouds of fallstreaks are often located in a layer of strong wind-shear, adiabatic lapse rate, large

Correspondence to: R. M. Worthington

(worth@kurasc.kyoto-u.ac.jp) vertical-wind variations and/or turbulence, and that they regenerate for tens of minutes or longer (Yagi, 1969; Kon et al., 1973; Heymsfield, 1975a, b; Buschmann and Albers, 2000) could imply KHI, breaking gravity waves (including breaking mountain waves) and/or some other process. Convective instabilities and latent heat transfer (Ludlam, 1956; Heymsfield, 1975a, b), volcanic aerosols (Sassen, 1992), and turbulence and humidity from aircraft (Sassen, 1991) may be implicated. The parent clouds sometimes rotate, with a "hole" of thinner cloud in the centre (Heymsfield, 1975a, b), which could imply overturning KHI or some type of rotor. Fallstreaks, like cirrus in general, may be more common and well-developed above mountains than above oceans (Ludlam, 1980; Penner et al., 2000), which would be evidence for mountain waves; nevertheless, mountain-wave cirrus itself often contains KHI (Ludlam, 1967). Fallstreaks are seen above oceans far from mountains (traditionally an omen of bad weather from, for example, an approaching warm front), which implies only KHI. Although all the above factors linked to fallstreaks are well known, it is difficult to pinpoint the precise cause of any individual fallstreak; Atlas (2001) writes, "one can only speculate as to the mechanism responsible".

The pointing direction of fallstreaks is an interesting detail, determined by the vertical-shear vector of horizontal wind (Magono et al., 1967; Harimaya, 1968; Heymsfield, 1975c). If there is no wind shear relative to the parent cloud, fallstreaks point straight down (Kon et al., 1973). In very strong shear, the fallstreaks can be almost horizontal (Yagi, 1969). The situation does, however, depend on the cause of the fallstreak. For KHI in the troposphere, with the wind shear vector in the same direction as the horizontal wind, and the parent cloud moving at the horizontal wind speed, the fallstreak points upwind (Fig. 1a) (Yagi, 1969); although, in practice, the shear vector causing KHI can take any direction relative to the horizontal wind vector, so the fallstreak can point in any direction. For fallstreaks caused by a mountain wave, the parent cloud remains relatively fixed as the air flows through it, and the fallstreak is simply carried 

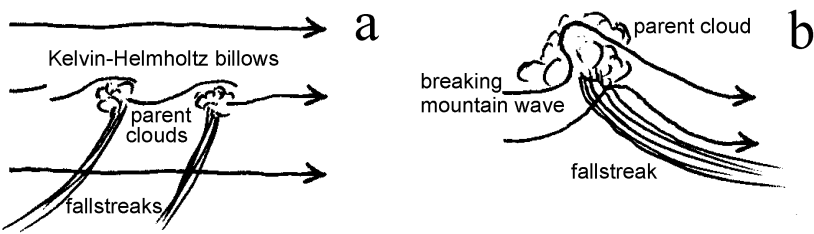

Fig. 1. Vertical cross sections showing the different pointing directions of fallstreaks caused by supersaturated air flowing through (a) Kelvin-Helmholtz instabilities and (b) breaking mountain waves. The fallstreak direction depends on the shear vector between the parent cloud and the fallstreak. In (a), the wind speed is increasing with height.

downwind (Fig. 1b). In both situations, the fallstreak has a characteristic curved "hook" or "comma" shape, due to the wind shear between parent cloud and fallstreak. Microphysics and ice particle growth rates may differ between Figs. $1 \mathrm{a}$ and $1 \mathrm{~b}$.

This paper studies the underlying cause of some large fallstreaks above western Europe on 15 June 1995, reanalysing published data (Worthington, 2001). These fallstreaks are the fair-weather type, in an otherwise clear sky, but the results may also apply to fallstreaks in complex rain and snow storms (Hobbs and Locatelli, 1978; Locatelli et al., 1983).

\section{Case study}

Figure 2a is a NOAA-12 visible-light satellite image, centred on Wales, at 07:30 UT on 15 June 1995. This image was studied briefly by Worthington (2001, Figs. 6, 8a-8c), who noted trapped mountain lee-waves, revealed by cloud bands (label "5"), that modulated the roughness of water waves on the sea. The wind is northerly, turning northwesterly near the ground on the east side of a high pressure weather system. However, this image also contains some remarkable fallstreaks.

An infrared version, Fig. 2b, reveals extensive thin high cloud, that is difficult to see in Fig. 2a. To the southwest (SW), there are aircraft contrails, consistent with air nearly saturated at some height in the upper troposphere. There are further contrails, SW above the Atlantic Ocean, that are not shown. To the west, there is high cloud downwind of Ireland. The Isle of Man, an isolated island with hills of $\sim 500 \mathrm{~m}$, is covered by cloud, with a plume of high cloud downwind for about $100 \mathrm{~km}$.

A strange feature, however, is the five or more small high clouds, rectangular and aligned SW-NE, above Wales in the centre of Fig. 2. The largest is $80 \mathrm{~km}$ east of label 5; others are to the south and east of label 5. Two have plumes of high cloud for tens of km downwind, sufficiently thick to cast shadows on the ground in Fig. 2a. The high parent clouds, with long trails of wispy high cloud downwind, show that these are fallstreaks.
Radiosondes at 05:00 ${ }^{1}$ and 10:00 UT, Fig. 3, confirm that the air has high humidity relative to water below $1 \mathrm{~km}$ height, and relative to ice at about $7 \mathrm{~km}$ height, where the temperature is $-30^{\circ} \mathrm{C}$. The upper region could be the height of the fallstreaks.

Are these fallstreaks caused by KHI, mountain waves, and/or some other effect? The large plume of cirrus downwind of the Isle of Man appears to be orographic (Ludlam, 1980). Also, the low-level cloud bands downwind of the Llŷn Peninsula, wavelength $\sim 6 \mathrm{~km}$, are mountain lee-wave clouds (Worthington, 2001) and the high, rectangular clouds are almost parallel to them. Although wind shear is variable with height and time, Figs. 3a, b, the fallstreaks drift downwind to the south in Fig. 2b, not upwind - similar to Fig. 1b rather than Fig. 1a, implying that they are caused by a mountain wave. Unfortunately, no side view, such as a photograph from the ground or an aircraft, is known to exist.

Three hours of VHF wind-profiling radar data are available, Fig. 4, fortunately centred on the time of Fig. 2. Despite the radar being upwind of most of the mountains, it shows vertical-wind variations typical of mountain waves (Worthington and Thomas, 1996). These disappear as the horizontal wind falls near zero at roughly $14 \mathrm{~km}$ height, which would be a critical layer for mountain waves. All of this is consistent with mountain waves as a cause of the fallstreaks in Fig. 2.

The SW-NE alignment of the parent clouds in Fig. 2 is curious, but may further strengthen the case for mountain waves. The parent clouds are at right angles to the northwesterly low-level wind; a long-term study by Worthington (1999) found that alignment of mountain waves above Wales is more dependent on boundary-layer wind structure than on details of mountain ridges. However, the largest parent cloud, giving the largest fallstreak, is above the high Berwyn Mountains ( $>800 \mathrm{~m}$ above sea level), which are also aligned SW-NE (upper-right part of Fig. 1 in Worthington, 1999). Other parent clouds seem to correlate with mountains Snowdon, Mynydd Preseli, Mynydd Du, Mynydd Eppynt and possibly the Black Mountains.

The distribution of high cloud bars in Fig. 2 can be explained in terms of the unusual boundary-layer structure at 07:30 UT, rather than by coincidence - although coincidence remains a possibility. Instead of normal overcast weather, with near-adiabatic lapse rate from sea level to 1$2 \mathrm{~km}$ height, higher than the mountain peaks (Worthington, 2002), the boundary layer is stable at the time of Fig. 2. Sunrise is at 03:53 UT, and the boundary layer remains stable at 05:00 UT, Fig. 3c. Even at 10:00 UT the convective boundary layer is only $500 \mathrm{~m}$ high. Stable, fast airflow impacting on the high Berwyn Mountains might locally force mountain waves more strongly, giving larger vertical displacement of streamlines throughout the troposphere, larger temperature perturbations, and more chance of overturning and turbulence in supersaturated air - creating the fallstreaks in Fig. 2b. This

\footnotetext{
${ }^{1}$ radiosonde launch times are nominal only and may be up to $1 \mathrm{~h}$ later
} 


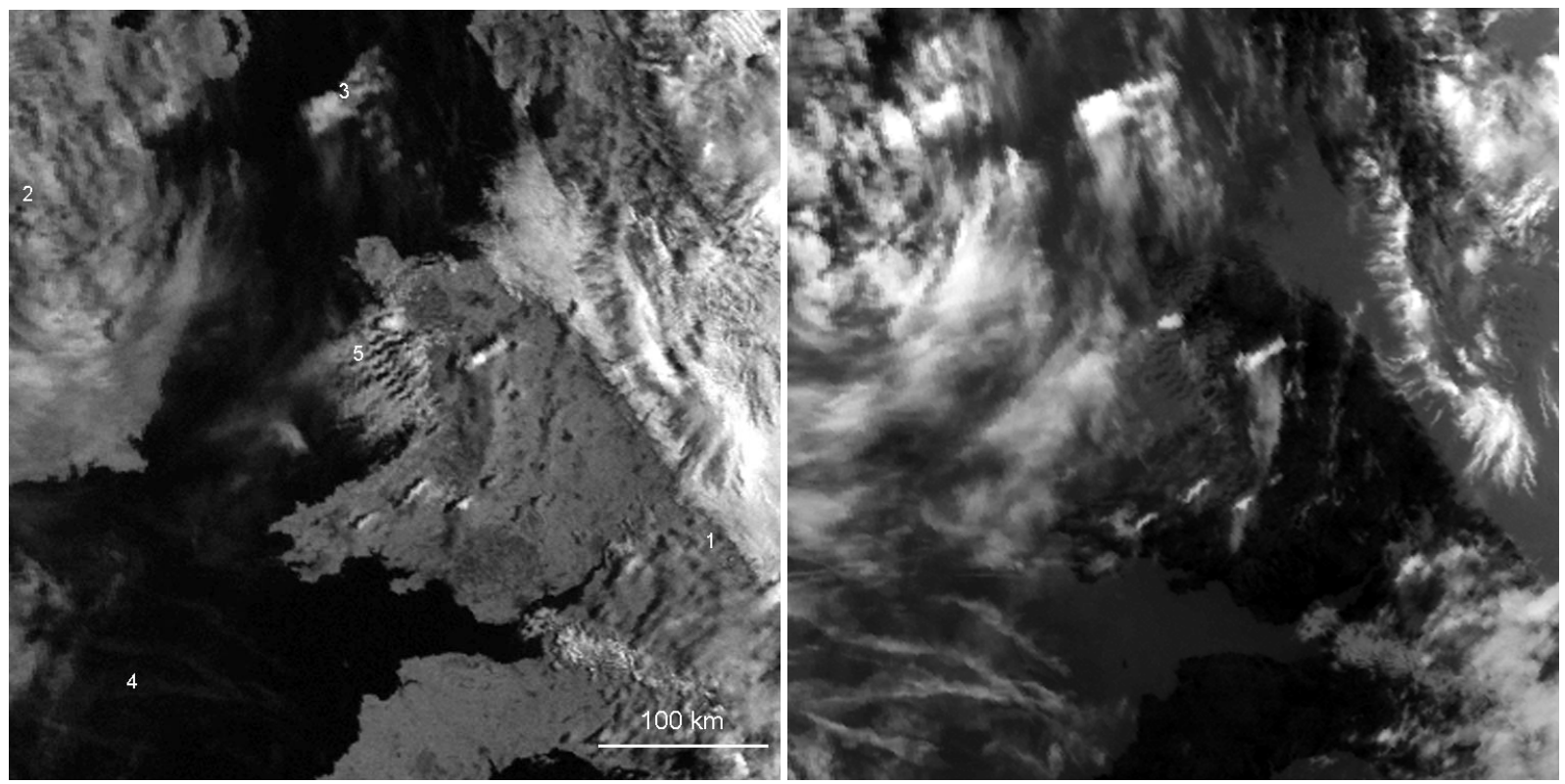

Fig. 2. (a) Visible-light satellite image at $07: 30 \mathrm{UT}$ on 15 June 1995 , approximately $7.5^{\circ}-1^{\circ} \mathrm{W}, 50.5^{\circ}-54.5^{\circ} \mathrm{N}$. North is at the top. It shows Wales in the centre, parts of England (1) and Ireland (2), and the Isle of Man (3). There are contrails (4), mountain lee-wave clouds (5) already discussed by Worthington (2001), and some strange cloud bars with the same alignment as the lee waves (the largest is about $80 \mathrm{~km}$ east of label 5). Image supplied by the Satellite Receiving Station, Dundee University, Scotland. (b) Infrared version of (a), revealing extensive thin high cloud, and fallstreaks downwind of two of the cloud bars.

suggests why the parent clouds are located where they are, their rectangular shape, and SW-NE alignment; the fallstreak parent clouds in the upper troposphere are above where the mountain waves are more strongly forced in the boundary layer. Unfortunately, there is only one image; an animation of the cloud motion would have been fascinating.

Whether the parent clouds in Fig. $2 \mathrm{~b}$ are caused not just by lifting, but also by wave-breaking turbulence, is not certain. Parent clouds of fallstreaks are reported to be always cumuluform, which suggests turbulence (Ludlam, 1980). Maybe the parent clouds here are rotors. VHF radar reveals a small patch of increased spectral width and turbulence near $14 \mathrm{~km}$ height (not shown); however the radar is not co-located with the fallstreaks, so wave breaking might occur at a lower height inland, where the mountains and mountain waves are larger. The exact ice/water composition of the parent clouds (Quante et al., 2000) is also uncertain. Survival of the fallstreaks for up to $60 \mathrm{~km}$ downwind depends on ambient conditions, which appear favourable given the extensive cirrus and contrails in Fig. 2b. Whether any fallstreaks reached the ground as light rain, from a clear sky, is not known; maybe they evaporated before reaching the ground. Nevertheless, at least the precise cause of one fallstreak event has, for possibly the first time, been narrowed down - in this case, to mountain waves.

\section{Significance for ice cloud formation}

Mountain waves are known to create extensive sheets of cirrus cloud (Ludlam 1980). If the results in Figs. 2-4 prove that breaking mountain waves also create fallstreaks of ice crystals, then there are some implications.

Orographic rain is increased by the Bergeron seederfeeder mechanism (e.g. Browning, 1974 for the region studied here). Falling ice crystals seed rainfall in supersaturated air, in the boundary layer and lower troposphere above mountains. Figure $2 \mathrm{~b}$ shows how breaking mountain waves may themselves create seeder ice crystals (Browning, 1974). Since even low hills may be able to create some mountain waves (Worthington et al., 2001), this mechanism could slightly enhance seeder clouds above low hills, further increasing rainfall.

Secondly, mountain waves often break at critical layers in the lower stratosphere, where the horizontal wind speed, above the jet stream, falls close to zero (Worthington and Thomas, 1996). In the same height region, mountain waves perturb stratospheric temperature, creating polar stratospheric clouds that may be a source of ozone depletion (e.g. Carslaw et al., 1998; Réchou et al., 1999). The stratosphere is too dry for fallstreaks to occur. However, if turbulent breaking of mountain waves can create additional ice clouds and under a broader range of temperature conditions as implied by the formation of fallstreaks in the troposphere - then whether mountain waves are breaking or non-breaking 


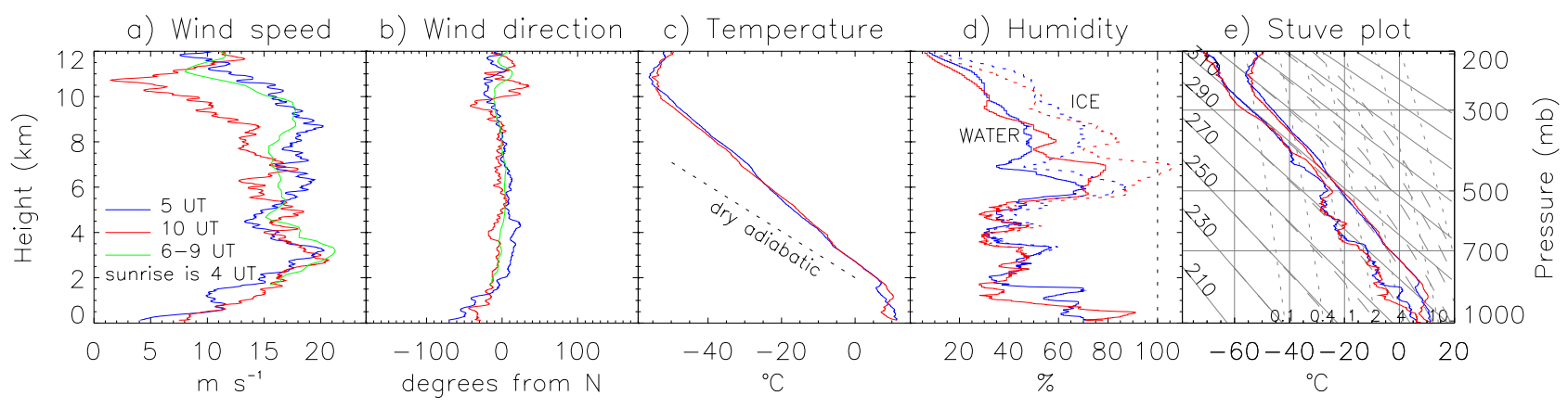

Fig. 3. Radiosonde profiles showing horizontal wind, temperature and humidity, a few hours before and after the time of Fig. 2. Blue and red lines are measured at 05:00 and 10:00 UT, respectively; green lines are by VHF radar averaged 05:50-09:00 UT. In (c), there is a marked variation in boundary-layer structure. The dotted line shows dry-adiabatic lapse rate. In (d), dotted lines show humidity relative to ice, for temperatures below $0^{\circ} \mathrm{C}$. The air is almost saturated relative to ice at a height of roughly $7 \mathrm{~km}$. In (e), diagonal solid, dashed and dotted lines show dry adiabats $(\mathrm{K})$, saturated adiabats, and saturated specific humidity $(\mathrm{g} / \mathrm{kg})$. Radiosondes were launched about $80 \mathrm{~km}$ south of label 5 in Fig. 2a.

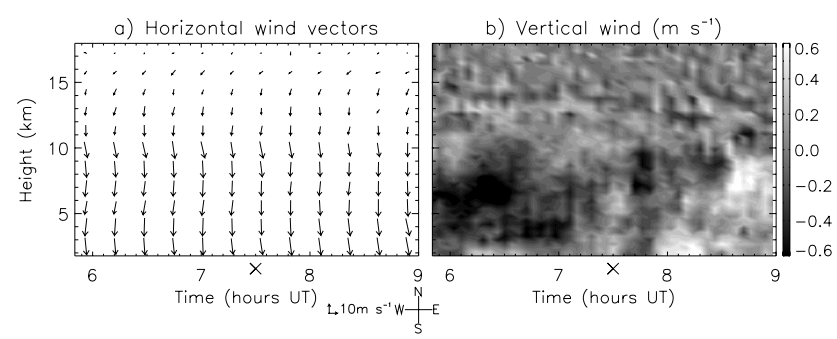

Fig. 4. Height-time plots of horizontal and vertical wind measured by VHF radar, centred on the time (marked $\times$ ) of Fig. 2 . The vertical wind shows some mountain waves, up to a height of roughly $14 \mathrm{~km}$ where the horizontal wind falls near zero. The radar is about $60 \mathrm{~km}$ south-east of label 5 in Fig. 2a.

in the stratosphere might alter the efficiency of ozone depletion.

\section{New interpretation of previous fallstreak studies}

Kon et al. (1973) show rows of fallstreaks (described as "virga", although virga may be in the lower troposphere and composed of liquid water, e.g. Fraser and Bohren, 1992; Sassen and Krueger, 1993). The fallstreaks, smaller than those in Fig. 2b, were linked to turbulence rather than any natural cloud-seeding effect. The fallstreaks appeared over the sea, so KHI and not mountain waves may have caused the turbulence. However, KHI billow clouds usually have a smooth appearance, unlike the cumuliform parent clouds with fallstreaks shown by Kon et al. One possibility is that the lines of parent clouds reveal instead only the turbulent core of some small KHI.

Yagi et al. (1968) show small spiral-shaped fallstreaks, pointing in a direction inconsistent with the wind shear vector, that could not be fully explained. This was above a mountainous area of Japan, and the fallstreak was at a height, $11 \mathrm{~km}$, where the wind had turned $\sim 90^{\circ}$ from its low-level direction (Fig. 2 of Yagi, 1969). There was also a line of cirrus cloud perpendicular to the low-level wind. Perhaps the turbulence and small fallstreaks on this occasion were linked to mountain-wave breaking at a critical layer (Worthington and Thomas, 1996; Worthington, 1998), consistent with a neutral lapse rate. The strange alignment of the fallstreaks would be explainable as they passed through, for example, a rotor at the height of wave breaking.

\section{Conclusions}

The underlying cause of some large fallstreak clouds is investigated using satellite images, radiosondes, and radar. All evidence indicates that these fallstreaks, at about $7 \mathrm{~km}$ height and temperature $-30^{\circ} \mathrm{C}$, are caused by air, already almost saturated relative to ice, that encounters the lifting and probably turbulence of a breaking mountain wave. The boundarylayer airflow incident on the mountains is stable and fast, a few hours after dawn before convection has time to develop. The case study confirms how mountain waves can produce ice crystals, as in the seeder-feeder effect on orographic rain. Whether mountain waves are breaking or nonbreaking might also affect their efficiency in producing polar stratospheric clouds and ozone depletion.

Acknowledgements. The author is supported by a fellowship from Japan Society for the Promotion of Science. The UK MST radar is a national facility of NERC, radiosondes were launched by the Met Office, both data sets were archived at BADC, copies of references were provided by RA-MW.

Topical Editor J.-P. Duvel thanks A. Heymsfield and another referee for their help in evaluating this paper.

\section{References}

Atlas, D.: Fallstreaks and their parent generators, Bull. Amer. Meteorol. Soc., 82, 477-480, 2001. 
Browning, K. A.: Mesoscale structure of rain systems in the British Isles, J. Meteorol. Soc. Japan, 52, 314-327, 1974.

Buschmann, N. and Albers, F.: Spatial inhomogeneities of cirrus clouds as derived from in situ ice particle measurements, Phys. Chem. Earth (B), 25, 77-81, 2000.

Carslaw, K. S. et al.: Increased stratospheric ozone depletion due to mountain-induced atmospheric waves, Nature, 391, 675-678, 1998.

Fraser, A. B. and Bohren, C. F.: Is virga rain that evaporates before reaching the ground?, Mon. Weath. Rev., 120, 1565-1571, 1992.

Gedzelman, S. D.: Angel hair cirrus, Weatherwise, 53, 20-27, 2000.

Harimaya, T.: On the shape of cirrus uncinus clouds: a numerical computation - Studies of cirrus clouds: Part III, J. Meteorol. Soc. Japan, 46, 272-279, 1968.

Heymsfield, A.: Cirrus uncinus generating cells and the evolution of cirriform clouds. Part 1: Aircraft observations of the growth of the ice phase, J. Atmos. Sci., 32, 799-808, 1975a.

Heymsfield, A.: Cirrus uncinus generating cells and the evolution of cirriform clouds. Part 2: The structure and circulations of the cirrus uncinus generating head, J. Atmos. Sci., 32, 809-819, 1975 b.

Heymsfield, A.: Cirrus uncinus generating cells and the evolution of cirriform clouds. Part 3: Numerical computations of the growth of the ice phase, J. Atmos. Sci., 32, 820-830, 1975c.

Hobbs, P. V. and Locatelli, J. D.: Rainbands, precipitation cores and generating cells in a cyclonic storm. J. Atmos. Sci., 35, 230-241, 1978.

Kon, H., Chiyu, T., and Magono, C.: Homogeneous generation of virga from altocumulus clouds, J. Meteorol. Soc. Japan, 51, 486$489,1973$.

Locatelli, J. D., Hobbs, P. V., and Biswas, K. R.: Precipitation from stratocumulus clouds affected by fallstreaks and artificial seeding, J. Clim. Appl. Meteorol., 22, 1393-1403, 1983.

Ludlam, F. H.: The forms of ice clouds: II, Q. J. R. Meteorol. Soc., 82, 257-265, 1956.

Ludlam, F. H.: Characteristics of billow clouds and their relation to clear-air turbulence. Q. J. R. Meteorol. Soc., 93, 419-435, 1967.

Ludlam, F. H.: Clouds and storms, The behavior and effect of water in the atmosphere, Pennsylvania State University Press, 1980.

Magono, C., Kikuchi, K., and Kajikawa, M.: Distribution of lowlevel cloud rows and three dimensional analysis of cirrus clouds - Clouds over the Pacific Ocean: Part II, J. Meteorol. Soc. Japan, 45, 467-477, 1967.

Penner, J. E., Lister, D. H., Griggs, D. J., Dokken, D. J., and Mc.
Farland, M.: Aviation and the Global Atmosphere, Ch. 3.4, Contrail occurrence and persistence and impact of aircraft exhaust on cirrus. Intergovernmental Panel on Climate Change, 2000.

Quante, M., Lemke, H., Flentje, H., Francis, P., and Pelon, J.: Boundaries and internal structure of mixed phase clouds as deduced from ground-based $95-\mathrm{GHz}$ radar and airborne lidar measurements, Phys. Chem. Earth (B), 25, 889-895, 2000.

Réchou, A., Barabash, V., Chilson, P., Kirkwood, S., Savitskaya, T., and Stebel, K.: Mountain wave motions determined by the Esrange MST radar, Ann. Geophysicae, 17, 957-970, 1999.

Sassen, K.: Aircraft-produced ice particles in a highly supercooled altocumulus cloud, J. Appl. Meteorol., 30, 765-775, 1991.

Sassen, K.: Evidence for liquid-phase cirrus cloud formation from volcanic aerosols - climatic implications, Science, 257, 516519, 1992.

Sassen, K. and Krueger, S. K.: Toward an empirical definition of virga: Comments on "Is virga rain that evaporates before reaching the ground?”, Mon. Weath. Rev., 121, 2426-2428, 1993.

Worthington, R. M.: Tropopausal turbulence caused by the breaking of mountain waves, J. Atmos. Sol. Terr. Phys., 60, 1543-1547, 1998.

Worthington, R. M.: Alignment of mountain wave patterns above Wales: A VHF radar study during 1990-1998, J. Geophys. Res., 104, 9199-9212, 1999.

Worthington, R. M.: Alignment of mountain lee waves viewed using NOAA AVHRR imagery, MST radar, and SAR, Int. J. Remote Sensing, 22, 1361-1374, 2001.

Worthington, R. M.: Mountain waves launched by convective activity within the boundary layer above mountains. Boundary-Layer Meteorol., in press, 2002.

Worthington, R. M. and Thomas, L.: Radar measurements of critical-layer absorption in mountain waves, Q. J. R. Meteorol. Soc., 122, 1263-1282, 1996.

Worthington, R. M., Muschinski, A., and Balsley, B. B.: Bias in mean vertical wind measured by VHF radars: Significance of radar location relative to mountains, J. Atmos. Sci., 58, 707-723, 2001.

Yagi, T.: On the relation between the shape of cirrus clouds and the static stability of the cloud level - Studies of cirrus clouds: Part IV, J. Meteorol. Soc. Japan, 47, 59-64, 1969.

Yagi, T., Harimaya, T., and Magono, C.: On the shape and movement of cirrus uncinus clouds by the trigonometric method utilizing stereophotographs - Studies of cirrus clouds: Part II, J. Meteorol. Soc. Japan, 46, 266-271, 1968. 